\title{
Long-stay in forensic-psychiatric care in the UK
}

\author{
Laurie Hare Duke ${ }^{1}$ Vivek Furtado ${ }^{2} \cdot$ Boliang Guo $^{1}$ Birgit Angela Völlm ${ }^{1,3}$
}

Received: 13 January 2017 / Accepted: 13 December 2017 / Published online: 31 January 2018

(c) The Author(s) 2018. This article is an open access publication

\begin{abstract}
Purpose Forensic services provide care for mentally disordered offenders. In England this is provided at three levels of security - low, medium and high. Significant number of patients within these settings remain detained for protracted periods of time. This is both very costly and restrictive for individuals. No national studies have been conducted on this subject in England.

Methods We employed a cross-sectional design using anonymised data from medical records departments in English secure forensic units. Data were collected from a large sample of medium secure patients $(n=1572)$ as well as the total high secure patient population ( $n=715)$ resident on the census date (01-04-2013). We defined long-stay as a stay of more than 10 years in high, 5 years in medium or 15 years in a mix of high and medium secure settings. Long-stay status was assessed against patient demographic and admission information.

Results We identified a significant proportion of long-stayers: $23.5 \%$ in high secure and $18.1 \%$ in medium secure care. Amongst medium secure units a large variation in long-stay prevalence was observed from 0 to $50 \%$. Results indicated that MHA section, admission source and current ward type were independent factors associated with long-stay status.

Conclusion This study identified a significant proportion of long-stayers in forensic settings in England. Sociodemographic factors identified in studies in individual settings may be less important than previously thought. The large variation in prevalence of long-stayers observed in the medium secure sample warrants further investigation.
\end{abstract}

Keywords Forensic $\cdot$ Secure setting $\cdot$ Mentally disordered offender $\cdot$ Length of stay $\cdot$ Characteristics

\section{Background}

The purpose of forensic-psychiatric care is to improve the mental health of mentally disordered offenders whilst reducing their risk of recidivism. Forensic-psychiatric services in England provide care and treatment for mentally disordered offenders in high, medium and low secure in-patient facilities as well as in the community. High secure units (HSUs) admit individuals detained under the Mental Health Act and who "require treatment under conditions of high security on

Birgit Angela Völlm

birgit.vollm@nottingham.ac.uk

1 Division of Psychiatry and Applied Psychology, School of Medicine, Institute of Mental Health, University of Nottingham, Jubilee Campus, Triumph Road, Nottingham NG7 2TU, UK

2 University of Warwick, Coventry, UK

3 Nottinghamshire Healthcare NHS Foundation Trust, Nottingham, UK account of their dangerous, violent or criminal propensities" [1]. Medium secure units (MSUs) were developed in the late 1970s to bridge the gap between high secure and general psychiatric care and are designed for those patients detained under the Mental Health Act who "pose a serious danger to the public" [1]. There are currently three high secure hospitals in England providing just over 700 beds and around 60 medium secure units providing around 3500 medium secure beds, with nearly $35 \%$ of those beds provided by the independent sector.

Since the 1950s there has been an increasing tendency towards deinstitutionalisation, with more patients being treated in community settings rather than as inpatients on general psychiatric hospitals. This process has been consistently associated with greater user satisfaction, increased met needs, and better outcomes on adherence to treatment, clinical symptoms and quality of life [2-5]. Whilst bed numbers have decreased in general psychiatric hospitals, they have actually increased in forensic-psychiatric services over the same period. 
A significant number of patients in secure units remain in care for extended periods of time. In addition, it has previously been found that between one and two-thirds of patients in high secure settings in the UK did not need that level of security [6-10]. Meanwhile it appears that the average length of stay $(\mathrm{LoS})$ within MSUs is on the rise [11] and it is similarly expected that a substantial proportion of patients will be placed under restrictions inappropriate to their level of risk.

There are strong ethical and financial concerns arising from potentially unnecessarily protracted stay in secure care. Secure settings are extremely restrictive, characterised by a loss of privacy, repetitive daily routines and low-stimulation environments. Although this may be necessary for some patients, it is of concern that some individuals remain in secure care for potentially inappropriate lengths of time. Secure care provision is also very expensive. MSUs in the UK, for example, cost around $£ 175,000$ per annum per patient, consuming $£ 1.2$ billion per annum. This is $1 \%$ of the entire NHS and $10 \%$ of the mental health budget $[1,12]$. Services must therefore aim to target only those individuals who require and will benefit from them.

At the same time, there is a suggestion that community based services do not provide sufficient levels of care for a sub-group of forensic patients, for whom 'deinstitutionalisation' may not be appropriate [13]. There has been some recognition of this group of patients at the international level. A review of the international literature revealed two European countries who have responded proactively to the needs of those patients who require long-term forensic-psychiatric care. In both the Netherlands and Germany long-stay units have been developed. It has been found that purposefully designed long-stay wards in the Netherlands may attract some cost savings compared to regular treatment wards as well as increased patient satisfaction due to their focus on quality of life [14]. Thus, identifying the characteristics of long-stay patients can support service improvements not only in order to better facilitate patient discharge, but also to aid in the development of more cost-effective pathways with better quality of life for patients genuinely requiring longer term care.

It is imperative therefore to identify the characteristics of long-stay patients and the factors behind their LoS in order to design appropriate service models to meet their particular needs. Previous studies in secure settings have identified a number of predictors of LoS: severity of index offence, psychopathology, referral from another secure or psychiatric setting, restriction orders and lack of facilities with lower levels of care and security $[11,15,16]$. However, these previous studies have been based upon samples from single units and no national studies are currently available on long-stay in forensic-psychiatric care in England. This may hinder the provision of services to support the discharge or to improve their quality of life within secure care of this patient group [17, 18].

\section{Aims and objectives}

Using a cross-sectional approach, this study aimed to: (1) identify the prevalence of long-stay in high secure units in England; (2) estimate the prevalence of long-stay in medium secure units in England and (3) identify individual-level sociodemographic and service factors associated with longstay amongst patients in high and medium secure care in England.

\section{Method}

\section{Design and approval}

A cross-sectional design was used, collecting anonymised data from all high secure units as well as a sample of medium secure units in England resident on the census date (01-04-2013). Individuals who were on trial leave at the time were excluded. Data were submitted to the research team in anonymised form and only included routinely collected data. As such the study did not require ethical approval and was deemed to fall within the remit of service evaluation by the sponsoring organisation.

\section{Definition of 'long-stay'}

Patients were categorised into long-stayers and non-longstay patients. Our piloting data from one high secure care setting suggested that just over $15 \%$ of patients stayed for over 10 years. For medium secure care, the literature suggests that $10-20 \%$ stay 5 years or longer. For our study, we aimed to capture the extreme end of long-stay; therefore, a cut-off that would capture around $15-20 \%$ of the population seemed appropriate. This is also the percentage of patients in long-stay services in countries where dedicated long-stay services exist. Allocation to 'long-stay' status was determined by total time of continuous stay in high and/or medium secure care, i.e. from admission to any such setting to census date. Long-stay was defined as five or more continuous years in medium secure care OR ten or more continuous years in high secure care OR a combination of the high and medium secure settings totalling 15 years or more of continuous secure care. Assignment to long-stay status was initially by review of admission date to current unit though if patients did not fall within the long-stay category based on their LoS in the current unit, we then enquired about admission source and, if admission source was high or medium secure care, whether the individual fulfils our criteria for long-stay through medical records staff or 
responsible clinicians. Unfortunately, date of first admission to secure care was not readily available in all cases, i.e. clinicians would be able to say with confidence that a particular individuals had been in services in excess of our cut-off but without being able to identify exact LoS overall in secure care; this is the reason why we were not able to use LoS as a continuous variable in the analyses.

\section{Selection of participating units}

All three high secure units in England were included.

A stratified cluster sampling frame was adopted for MSUs with 23 units sampled. This included 14 NHS and 9 independent units, drawn according to geographical region (according to boundaries of the then 10 Strategic Health Authorities), size and specialisation, with oversampling of units specialising in particular patient groups (e.g. patients with intellectual disabilities). This sample represents approximately $40 \%$ of all MSUs in England. One medium secure unit was included in regions with 1 to 3 units, 2 in regions with 4 or 5 units, 3 in regions with 6 or 7 units, 4 in regions with 8 or 9 units and 5 in regions with 10 or more medium secure units. Based on patient numbers, $11(48 \%)$ of these units were classed as small ( $\leq 50$ patients), 7 (30\%) were medium-sized (51-99 patients) and 5 (22\%) were large ( $\geq 100$ patients). Units were located across all English regions: North East ( $n=1)$, North West (4), Yorkshire and the Humber (2), East Midlands (2), West Midlands (2), East of England (4), London (3), South East (2), South Central (1), South West (2).

\section{Data collected}

Data for both HSUs and MSUs were collected through medical records departments on length of stay and basic patient and admission characteristics. Data collected were based on information known to be readily available from administrative systems on the basis of a pilot trial conducted in one HSU and one MSU. This included the following variables: date of admission to current unit, age, gender, ethnic class (White, Black, Asian, mixed, other), admission source, current Mental Health Act (MHA) section; diagnostic specification of current ward [mental illness, personality disorder (PD), comorbidity, intellectual disability (ID), neuropsychiatry, mixed diagnosis, other, cannot assign] and stage of treatment specification of current ward (admission/assessment, treatment, high dependency, long-stay/slow stream, pre-discharge/rehab, mixed assessment/treatment, other, cannot assign).

\section{Data analysis}

Admission source was collapsed into community (any nonsecure psychiatric settings, including Psychiatric Intensive Care Units, non-institutional settings, police stations), low, medium and high secure settings and prison. MHA section was categorised as civil/quasi-civil (s2, 3, 37, 37(N), 41(5), 47), hospital orders with restriction (s37/41, CPIA), prison transfer (s47/49, 48/49), pre-sentencing (s35, 36, 38) and other. $^{1}$

Data analysis was conducted separately for patients in high and medium secure settings as factors determining length of stay might be different in both settings, and only the former constitutes the full population. Results presented for the medium secure analysis are adjusted for sampling weights. Summary statistics were taken of all included variables.

National level information on the demographics and service use variables used in the sampling stratification is currently unavailable, which precluded adjustment for unequal probability of selection within the medium secure sample. The variability of long-stay status across units was first investigated in a two-level logistic regression with the secure unit as the level two analytical unit. Results showed no significant unit-level variability amongst HSUs, but statistically significant variability among MSUs ( $v a r=0.491,95 \%$ CI 0.186-1.292, intra-class correlation: $13.0 \%$ ). Exploratory analysis further showed non-significant region-level variance among units. Therefore, a general logistic regression was used to explore the association between long-stay and various influential factors for the high secure sample and a two-level logistic regression was used for the medium secure sample. As exploratory analysis showed there were some missing values for some influential factors (ethnic class: $7.4 \%$, admission source: $9.1 \%$ ), the robustness of the results was assessed by comparing the results of modelling data with missing covariates imputed by means of multiple imputation. All analysis was conducted using STATA 15.

For the high secure sample, univariate analysis was conducted with each factor entered individually into a logistic regression model to allow comparison of associations with and without adjusting other factors. For the medium secure sample a series of two-level logistic regressions were run,

\footnotetext{
1 The different sections of the MHA differ with regards to power of decision-making regarding transfer and discharge, possibility of move back to prison, amongst other things. On the most simple level those sections designated here to the 'civil/quasi-civil' category allow the clinical team to decide upon the patient's placement, while patients on restriction order require agreement by the Ministry of Justice for any transfers or discharge. Those on prison transfer orders can be moved back to prison as long as their sentence has not been served in full yet.
} 
with the secure unit entered as the level 2 analytical unit. All factors were subsequently entered simultaneously into a multivariate model.

As this study is exploratory, no hypotheses were made regarding the analysis.

\section{Results}

\section{Prevalence of long-stay}

According to our criteria, the prevalence of long-stay in across all three English high secure settings was $23.5 \%$, ranging from 21.6 to $26.5 \%$. Within the medium secure sample, the prevalence of long-stay was $18.1 \%$. There was a wide degree of variation between the medium secure units in our sample, with long-stay prevalence ranging from 0 to $50 \%$. With sampling weights and adjustment for unitlevel variance, the predicted probability for long-stay in the medium secure sample was $16.9 \%$ (95\% CI $12.7 \%, 21.1 \%$ ) (Table 1).

\section{Factors associated with long-stay status}

Variables entered in logistic models included MHA section and admission source; for the high secure sample ward diagnostic category was entered additionally and for the medium secure sample ward pathway category. For the high secure analysis the categories 'low secure unit' from admission source and 'pre-sentencing' and 'other' from the MHA section variable were omitted given inadequate number of longstay cases; the latter two categories were also omitted from the medium secure analysis.

\section{High secure care}

Results for the high secure population are shown in Table 2. The multivariate analysis found that demographic variables (gender and ethnic class) were not significantly associated with long-stay. For ethnic class, additional analysis of white patients compared to non-white was also nonsignificant (not shown in table). Compared with patients admitted on s37/41, other MHA section types were associated with a significantly reduced likelihood of long-stay status by over half. Those with a civil/quasi-civil section had $42 \%$ reduced odds and patients on a prison transfer had $68 \%$ reduced odds. Admission source demonstrated a significantly increased likelihood of long-stay against prison admissions for previous high secure cases and community admissions with medium secure admissions being non-significant ( $\mathrm{OR}=1.257, p=.369)$. It should be noted that there were only 5 cases admitted from the community in the high secure sample and estimates may not be reliable for this group. Diagnostic ward categorisation was a significant factor when comparing intellectual disability against personality disorder wards with cases from the latter presenting with reduced likelihood of prolonged stay. It may also be noted that patients on intellectual disability ward were also more likely to be long-stayers compared to mixed type and mental illness wards at the marginal significance level $(p=.081$ and 0.076 , respectively, not shown in Table 2).

\section{Medium secure care}

Similarly to the high secure population, the multivariate results for the medium secure sample in Table 3 show that demographic variables (gender and ethnic class) were not significantly associated with long-stay. For ethnic class, additional analysis of white patients compared to non-white was also non-significant (not shown in table). Regarding MHA section, compared with patients sectioned on hospital orders with restrictions, those on civil/quasi-civil section had $63 \%$ reduced odds of being a long-stayer and the odds were reduced by $65 \%$ for prison transfer patients. Admission source was also a significant factor. Compared to prisonadmitted patients, cases arriving from medium and high secure settings had approximately eight times the odds of being a long-stayer. For ward diagnostic category, patients in learning disability wards showed increased odds of long-stay compared to all other ward types, though none of the results reached significance level.

\section{Discussion}

This study sought to assess the prevalence of long-stay as well as some of the key determinants of long-stay status within high and medium secure care settings in England. According to our specified criteria, 24\% of patients within high secure units were classified as long-stayers and an estimated $17.4 \%$ in medium secure. There is limited research identifying how many patients stay for extended periods of time in high or medium secure hospitals in England and comparisons with previous studies are difficult to draw as previous research has used different cut-offs for 'long-stay', calculated LoS in patients' current unit only rather than continuous care, and sampled from single units.

In high secure care, Dell et al. [16] found that $44.4 \%$ of patients had exceeded the average LoS of 8 years in their study at one high secure hospital. This would appear to be a higher figure than ours though their study used a lower LoS cut-off; in addition, the data of that study is 20 years old now and policy and pathways have changed - not least has the accelerated discharge programme since taken place [19] targeting some of the residents in the Dell et al. [16] study. 
Table 1 Frequencies of patient, pathway and MHA section factors in the high and medium secure samples

\begin{tabular}{|c|c|c|c|c|}
\hline \multirow[t]{2}{*}{ Patient, pathway and MHA section factors } & \multicolumn{2}{|l|}{ High security } & \multicolumn{2}{|l|}{ Medium security } \\
\hline & Long-stay patients $(n=168)$ & $\begin{array}{l}\text { Non-long-stay } \\
\text { patients }(n=547)\end{array}$ & Long-stay patients $(n=285)$ & $\begin{array}{l}\text { Non-long- } \\
\text { stay patients } \\
(n=1287)\end{array}$ \\
\hline \multicolumn{5}{|l|}{ Provider, $n(\%)$} \\
\hline NHS & & & $178(62)$ & $915(71)$ \\
\hline Independent & & & $107(38)$ & $372(29)$ \\
\hline $\mathrm{LoS}$ in current unit (days), median (P25, P75) & $4294(2088,5844)$ & $1332(628,2161)$ & $1560(605,2383)$ & $438(168,838)$ \\
\hline $\begin{array}{l}\text { LoS in current unit (months), median (P25, } \\
\text { P75) }\end{array}$ & $141(69,192)$ & $44(21,71)$ & $51(20,78)$ & $14(6,28)$ \\
\hline Age, mean (SD) & $45.43(9.67)$ & $36.15(9.72)$ & $43.87(11.74)$ & $34.68(11.21)$ \\
\hline \multicolumn{5}{|l|}{ Gender, $n(\%)$} \\
\hline Male & $157(93.5)$ & $514(94.0)$ & $240(84.2)$ & $1049(81.5)$ \\
\hline Female & $11(6.5)$ & $33(6.0)$ & $45(15.8)$ & $238(18.8)$ \\
\hline \multicolumn{5}{|l|}{ Ethnic class, $n(\%)$} \\
\hline White & $128(76.7)$ & $404(75.0)$ & $216(77.8)$ & $808(68.6)$ \\
\hline Black & $23(13.8)$ & $75(13.9)$ & $39(14.1)$ & $208(17.6)$ \\
\hline Asian & $9(5.4)$ & $22(4.1)$ & $9(3.2)$ & $81(6.9)$ \\
\hline Mixed & $6(3.6)$ & $32(5.9)$ & $12(4.4)$ & $61(5.2)$ \\
\hline Other & $1(<1)$ & $6(1.1)$ & $1(<1)$ & $20(1.7)$ \\
\hline \multicolumn{5}{|l|}{ Region, $n(\%)$} \\
\hline East Midlands & & & $27(9.4)$ & $208(16.1)$ \\
\hline East of England & & & $50(17.5)$ & $144(11.1)$ \\
\hline North East & & & $19(6.6)$ & $58(4.5)$ \\
\hline North West & & & $60(21.0)$ & $217(16.8)$ \\
\hline Yorkshire & & & $48(16.8)$ & $108(8.3)$ \\
\hline West Midlands & & & $6(2.1)$ & $134(10.4)$ \\
\hline London & & & $46(16.1)$ & 254 (19.7) \\
\hline South East & & & $7(2.4)$ & $54(4.2)$ \\
\hline South West & & & $16(5.6)$ & $81(6.2)$ \\
\hline South Central & & & $6(2.1)$ & $29(2.2)$ \\
\hline \multicolumn{5}{|l|}{ MHA section, $n(\%)$} \\
\hline Civil/quasi-civil & $30(17.9)$ & $111(20.3)$ & $81(28.2)$ & $492(38.2)$ \\
\hline Hospital order with restrictions & $108(64.3)$ & $205(37.5)$ & $185(64.9)$ & $516(40.1)$ \\
\hline Prison transfer & $30(17.9)$ & $227(41.5)$ & $19(6.7)$ & $242(18.8)$ \\
\hline Pre-sentencing & 0 & $4(0.7)$ & 0 & $17(1.3)$ \\
\hline Other & 0 & 0 & 0 & $20(1.6)$ \\
\hline \multicolumn{5}{|l|}{ Admission source, $n(\%)$} \\
\hline Community & $4(2.5)$ & $1(<1)$ & $12(4.7)$ & $179(15.3)$ \\
\hline Prison & $65(41.1)$ & $367(70.3)$ & $46(18.0)$ & $602(51.3)$ \\
\hline Low secure unit & 0 & $2(<1)$ & $8(3.1)$ & $119(10.1)$ \\
\hline Medium secure unit & $51(32.2)$ & $137(26.2)$ & $118(46.1)$ & $192(16.4)$ \\
\hline High secure unit & $38(24.1)$ & $15(2.9)$ & $72(28.1)$ & $81(6.9)$ \\
\hline \multicolumn{5}{|l|}{ Ward diagnostic category, $n(\%)$} \\
\hline Mental illness & $78(46.4)$ & $245(44.8)$ & $132(46.3)$ & $472(36.7)$ \\
\hline Personality disorder & $48(28.6)$ & $209(38.2)$ & $20(7.0)$ & $80(6.2)$ \\
\hline Learning difficulties & $24(14.3)$ & $34(6.2)$ & $31(10.9)$ & $143(11.1)$ \\
\hline Mixed/other & $18(10.7)$ & $59(10.9)$ & $102(35.8)$ & $592(46.0)$ \\
\hline \multicolumn{5}{|l|}{ Ward pathway category, $n(\%)$} \\
\hline Admission & $8(4.8)$ & $46(8.4)$ & $9(3.2)$ & 201 (15.6) \\
\hline Treatment & $87(51.8)$ & $294(53.7)$ & $83(20.1)$ & $382(29.7)$ \\
\hline
\end{tabular}


Table 1 (continued)

\begin{tabular}{|c|c|c|c|c|}
\hline \multirow[t]{2}{*}{ Patient, pathway and MHA section factors } & \multicolumn{2}{|l|}{ High security } & \multicolumn{2}{|l|}{ Medium security } \\
\hline & Long-stay patients $(n=168)$ & $\begin{array}{l}\text { Non-long-stay } \\
\text { patients }(n=547)\end{array}$ & Long-stay patients $(n=285)$ & $\begin{array}{l}\text { Non-long- } \\
\text { stay patients } \\
(n=1287)\end{array}$ \\
\hline High dependency & $26(15.5)$ & $72(13.2)$ & $1(<1)$ & $28(2.2)$ \\
\hline Slow/rehab & $19(11.3)$ & $61(11.2)$ & $101(35.4)$ & $221(17.2)$ \\
\hline Mixed/other & $28(16.7)$ & 74 (13.5) & $91(31.9)$ & $455(35.4)$ \\
\hline
\end{tabular}

Table 2 Long-stay status and associated factors in high secure care

\begin{tabular}{|c|c|c|}
\hline Parameters & Bivariate, odds ratio (SE) & Multivariate, odds ratio (SE) \\
\hline \multicolumn{3}{|l|}{ Gender } \\
\hline Female & 1.000 & \\
\hline Male & $0.916(0.329)$ & $1.072(0.548)$ \\
\hline \multicolumn{3}{|l|}{ Ethnic class } \\
\hline White & 1.000 & \\
\hline Black & $0.967(0.250)$ & $0.577(0.191)$ \\
\hline Asian & $1.291(0.527)$ & $1.095(0.492)$ \\
\hline Mixed & $0.591(0.270)$ & $0.517(0.267)$ \\
\hline Other & $0.526(0.570)$ & $0.266(0.336)$ \\
\hline \multicolumn{3}{|l|}{ MHA } \\
\hline Hospital order w/restrictions & 1.000 & 1.000 \\
\hline Civil/ quasi-civil & $0.513(0.121)^{* *}$ & $0.579(0.158)^{*}$ \\
\hline Prison transfer & $0.250(0.057) * * *$ & $0.328(0.088) * * *$ \\
\hline \multicolumn{3}{|l|}{ Admission source } \\
\hline Prison & 1.000 & 1.000 \\
\hline Community & $22.584(25.432)^{* *}$ & $15.379(18.134)^{*}$ \\
\hline Medium secure & $2.101(0.445)^{* * *}$ & $1.257(0.320)$ \\
\hline High secure & $14.303(4.767) * * *$ & $11.235(3.986)^{* * *}$ \\
\hline \multicolumn{3}{|l|}{ Ward pathway category } \\
\hline Mixed/other & 1.000 & \\
\hline Admission & $0.459(0.203)$ & $0.476(0.265)$ \\
\hline Treatment & $0.782(0.198)$ & $0.926(0.288)$ \\
\hline High dependency & $0.954(0.304)$ & $0.755(0.292)$ \\
\hline Slow/rehab & $0.823(0.283)$ & $0.680(0.277)$ \\
\hline \multicolumn{3}{|l|}{ Ward diagnostic category } \\
\hline Intellectual disability & 1.000 & 1.000 \\
\hline Mixed/other & $0.432(0.163)^{*}$ & $0.445(0.206)$ \\
\hline Personality disorder & $0.325(0.101)^{* * *}$ & $0.422(0.159)^{*}$ \\
\hline Mental illness & $0.451(0.133)^{* *}$ & $0.530(0.189)$ \\
\hline
\end{tabular}

$* p<.05, * * p<.01, * * * p<.001$
Meanwhile in medium secure settings studies using our cut-off of 5 years for LoS in England reported figures of between just under 10 to just over 20\% [20-22]. Two of these figures are lower than ours but these used current unit LoS and sampled from single units. Given the huge variation in prevalence between both units in our study, it is clear that research in one single setting does not provide a useful national picture of LoS.
The large variation in prevalence of long-stay for medium secure care is worth noting. One of the units included here had a ward set up specifically for those leaving high secure care as part of the accelerated discharge programme-therefore, a higher percentage of long-stayers in this unit was expected. On the other hand, about two-thirds of the high and half of the medium secure long-stay group were admitted from the same or lower levels of security. Variation in 
Table 3 Long-stay status and associated factors in medium secure care

\begin{tabular}{|c|c|c|}
\hline Parameters & Bivariate, odds ratio (SE) & Multivariate, odds ratio (SE) \\
\hline \multicolumn{3}{|l|}{ Gender } \\
\hline Female & 1.000 & \\
\hline Male & $0.927(0.212)$ & $0.744(0.281)$ \\
\hline \multicolumn{3}{|l|}{ Ethnic class } \\
\hline White & 1.000 & \\
\hline Black & $0.945(0.191)$ & $0.962(0.313)$ \\
\hline Asian & $0.808(0.263)$ & $1.049(0.516)$ \\
\hline Mixed & $0.916(0.391)$ & $0.814(0.288)$ \\
\hline Other & $0.335(0.239)$ & $0.571(0.486)$ \\
\hline \multicolumn{3}{|l|}{ Provider } \\
\hline NHS & 1.000 & \\
\hline Independent & $1.376(0.516)$ & $1.072(0.303)$ \\
\hline \multicolumn{3}{|l|}{ MHA } \\
\hline Hospital order w/restrictions & 1.000 & \\
\hline Civil/ quasi-civil & $0.339(0.080)^{* * *}$ & $0.365(0.106)^{* * *}$ \\
\hline Prison transfer & $0.231(0.087)^{* * *}$ & $0.347(0.099) * * *$ \\
\hline \multicolumn{3}{|l|}{ Admission source } \\
\hline Prison & 1.000 & \\
\hline Community & $0.521(0.206)$ & $0.518(0.209)$ \\
\hline Low secure & $0.526(0.278)$ & $7.960(1.751)$ \\
\hline Medium secure & $8.106(2.621)^{* * *}$ & $0.644(0.319)^{* * *}$ \\
\hline High secure & $8.347(2.285)^{* * *}$ & $8.087(2.316)^{* * *}$ \\
\hline \multicolumn{3}{|l|}{ Ward pathway category } \\
\hline Mixed/other & 1.000 & \\
\hline Admission & $0.362(0.238)$ & $0.733(0.432)$ \\
\hline Treatment & $0.914(0.263)$ & $1.122(0.450)$ \\
\hline High dependency & $0.307(0.197)$ & $1.569(1.801)$ \\
\hline Slow/rehab & $1.468(0.946)$ & $1.784(1.231)$ \\
\hline \multicolumn{3}{|l|}{ Ward diagnostic category } \\
\hline Intellectual disability & 1.000 & \\
\hline Mixed/other & $0.757(0.258)$ & $0.544(0.180)$ \\
\hline Personality disorder & $0.863(0.298)$ & $0.533(0.312)$ \\
\hline Mental illness & $1.075(0.281)$ & $0.790(0.360)$ \\
\hline
\end{tabular}

$* p<.05, * * p<.01, * * * p<.001$ long-stay numbers may arise as a result of the different patient groups (e.g. those with PD or LD) catered for; some studies have also identified variation in admission rates by geographical location due to differences in social deprivation, ethnic class and availability of low secure beds [23]. These factors are unlikely to fully account for the differences in long-stay though, particularly as we did not find some of them, e.g. ethnic class, to be associated with longstay status. There are no national standards with regard to admission criteria to medium secure care beyond the patient being a "serious danger to the public" [1] and it is possible, though this cannot be confirmed by our study, that individual units adopt their own (implicit or explicit) criteria, such as not admitting patients with little prospect of moving on to less secure settings or being discharged. Alternatively, it is possible that the interventions offered in units with a higher proportion of long-stayers are less effective in allowing patients to move on.

Our final models suggested that MHA section, admission source and current ward type were each independently associated with long-stay status. Previous studies have produced somewhat conflicting findings with regard to associations between sociodemographic factors and LoS though most have not found such a relationship. Two previous studies have identified that non-white patients had a shorter LoS than white ethnic groups [21,22] and studies that looked at gender differences have found shorter LoS in females [24]. Notably, their longer term outcome seems to be worse though [25]. We did not find any difference between long-stayers and non-long-stayers on gender or 
ethnic class; the higher percentage of white ethnic class in long-stayers in the medium secure setting failed to reach statistical significance. Unsurprisingly, long-stayers were older than non-long-stayers in both, high and medium secure care. The large number of older patients, with about one-third of the long-stay population being over 50 , has important implications for the service planning for this patient group.

In line with other research in individual settings [15, $24,26]$ our national study has also identified an association between MHA and long-stay status in both, medium and high secure patients with significantly more patients in the long-stay groups on hospital orders with restrictions and less on prison transfers. This reflects the practical realities of this section in that it does not allow return transfer back to prison for those who may no longer benefit from hospital treatment. Compared to those civil sections (or quasi-civil sections, such as hospital orders without restrictions) these patients also require Ministry of Justice approval for moves to other secure settings, another reason for the potential delay in their transfer. The data on admission source additionally reflects potential challenges in the smooth transfer of this patient group along a pathway from more to less secure settings as identified by others (e.g. Tetley et al. for PD patients [27]). Such pathways typically identify the journey of a patient from more to less secure units, and ideally back into the community. If in the future dedicated long-stay services were developed in England, decisions would also have to be made at which point such services would become part of this pathway.

A number of authors have suggested that a lack of secure services for LD patients might contribute to their higher LoS [28] and most studies have found that severe mental illness was associated with longer and PD with shorter LoS [11]. This study did not use formal diagnostic data, but diagnostic ward type was used as a proxy and reflects these findings. It should be noted, though, that diagnostic ward type concerns whether particular groups will be admitted, not that the unit will be entirely populated by patients with that diagnosis and proportions may vary between units.

\section{Limitations}

This was a cross-sectional study, limiting any causal inference. Lack of diagnostic data meant we had to refer to ward diagnostic classification as a proxy measure which may be unreliable. Demographic and admissions data were restricted to that which was readily obtainable within the sample. Many other variables than which were modelled in this study are likely to explain variation in long-stay.

\section{Conclusion}

There is a large number of patients resident in English high or medium secure settings who remain in those settings for prolonged periods of time and the prevalence of long-stay varied greatly between medium secure settings suggesting potentially a lack of consistency in admission criteria and/or discharge procedures. The large number of patients admitted from the same or lower levels of security is of concern and suggests a trajectory of movement within the system rather than progression outwards. These experiences can cause a significant amount of distress for patients and carers. In order to facilitate more effective treatment and discharge of long-stay patients from secure settings, further investigation of the characteristics and needs of this patient group is required in order to identify suitable therapeutic interventions. A national strategy for the management of this patient group might assist in this.

Acknowledgements The study was funded by the National Institute for Health Research; reference HS\&DR 11/1024/06. The views and opinions expressed therein are those of the authors and do not necessarily reflect those of the HS\&DR Programme, NIHR, NHS or Department of Health. The sponsor was Nottinghamshire Healthcare NHS Foundation Trust.

Conflict of interest There are no conflicts of interests to disclose for this study.

Open Access This article is distributed under the terms of the Creative Commons Attribution 4.0 International License (http://creativeco mmons.org/licenses/by/4.0/), which permits unrestricted use, distribution, and reproduction in any medium, provided you give appropriate credit to the original author(s) and the source, provide a link to the Creative Commons license, and indicate if changes were made.

\section{References}

1. Rutherford M, Duggan S (2008) Forensic mental health services: facts and figures on current provision. Br J Forensic Pract 10(4), 4-10. https://doi.org/10.1108/14636646200800020

2. Braun P, Kochansky G, Shapiro R, Greenberg S, Gudeman JE, Johnson S, Shore MF (1981) Overview: deinstitutionalization of psychiatric patients, a critical review of outcome studies. Am J Psychiatry 138(6):736-749. https://doi.org/10.1176/ ajp.138.6.736

3. Bond DGR, Drake DRE, Mueser DKT, Latimer DE (2012) Assertive community treatment for people with severe mental illness. Dis Manag Health Outcomes 9(3):141-159. https://doi. org/10.2165/00115677-200109030-00003

4. Leff J (1993) Evaluating the transfer of care from psychiatric hospitals to district-based services. Br J Psychiatry Suppl 19:6

5. Killaspy $\mathrm{H}$ (2006). From the asylum to community care: learning from experience. Br Med Bull, 79-80, 245-258. https://doi. org $/ 10.1093 / \mathrm{bmb} / \mathrm{ld} 1017$

6. Maden A, Curle C, Meux CJ, Burrow S et al (1993) The treatment and security needs of patients in special hospitals. Crim Behav Ment Health 3(4):290-306 
7. Reed J (1997) The need for longer term psychiatric care in medium or low security. Crim Behav Ment Health 7(3):201-212. https://doi.org/10.1002/cbm.173

8. Pierzchniak P, Farnham F, de Taranto N, Bull D, Gill H, Bester P, McCallum A, Kennedy H (1999) Assessing the needs of patients in secure settings: a multi-disciplinary approach. J Forensic Psychiatry 10(2):343-354. https://doi.org/10.1080/095851899084036 88

9. Shaw J, Davies J, Morey H (2001) An assessment of the security, dependency and treatment needs of all patients in secure services in a UK health region. J Forensic Psychiatry 12(3):610-637. https ://doi.org/10.1080/09585180127380

10. Harty M-A, Shaw J, Thomas S, Dolan M, Davies L, Thornicroft G, Carlisle J, Moreno M, Leese M, Applyby L, Jones P (2004) The security, clinical and social needs of patients in high security psychiatric hospitals in England. J Forensic Psychiatry Psychol 15(2):208-221. https://doi.org/10.1080/14789940410001703967

11. Shah A, Waldron G, Boast N, Coid JW, Ullrich S (2011) Factors associated with length of admission at a medium secure forensic psychiatric unit. J Forensic Psychiatry Psychol 22(4):496-512. https://doi.org/10.1080/14789949.2011.594902

12. Walker J, Amos T, Knowles P, Batson S, Craissati J (2012) Finance. Putting a price on psychiatric care. Health Serv J 122(6296):22-24

13. Lamb HR (2001) Deinstitutionalization at the beginning of the new millennium. In: Lamb HR, Weinberger L (eds) New direction for mental health services. Deinstitutionalization: promise and problems. Jossey-Bass, San Francisco, CA, pp 3-20

14. Perik J (2002) Longstay in der Praxis [Long stay in Practice]. Recht Psychiatrie 20(1):23-26

15. Brown K, Fahy T (2009) Medium secure units: pathways of care and time to discharge over a four-year period in South London. J Forensic Psychiatry Psychol 20(2):268-277. https://doi. org/10.1080/14789940802327291

16. Dell S, Robertson G, Parker E (1987) Detention in Broadmoor. Factors in length of stay. Br J Psychiatry J Ment Sci 150:824-827

17. Mason T (1999) The psychiatric 'supermax'?: long-term, highsecurity psychiatric services. Int J Law Psychiatry 22(2):155-166
18. Salize HJ, Dressing H (2005) Coercion, involuntary treatment and quality of mental health care: is there any link? Curr Opin Psychiatry 18(5):576-584. https://doi.org/10.1097/01.yco.00001 79501.69053.d3

19. Department of Health (2000) Report of the Review of Security at the High Security Hospitals. HMSO, London

20. Jacques J, Spencer SJ, Gilluley P (2010) Long-term care needs in male medium security. Br J Forensic Pract 12(3):37-44

21. Shah A, Waldron G, Boast N, Coid JW, Ullrich S (2011) Factors associated with length of admission at a medium secure forensic psychiatric unit. J Forensic Psychiatry Psychol 22(4):496-512

22. Edwards J, Steed P, Murray K (2002) Clinical and forensic outcome 2 years and 5 years after admission to a medium secure unit. J Forensic Psychiatry 13(1):68-87

23. Coid J, Kahtan N, Gault S, Cook A, Jarman B (2001) Medium secure forensic psychiatry services: Comparison of seven English health regions. Br J Psychiatry 178(1):55-61

24. Davoren M, Byrne O, O'Connell P, O'Neill H, O'Reilly K, Kennedy HG (2015) Factors affecting length of stay in forensic hospital setting: need for therapeutic security and course of admission. BMC Psychiatry 15:301

25. Sahota S, Davies S, Duggan C, Clarke M, Huband N, Owen V (2010) Women Admitted to Medium Secure Care: Their Admission Characteristics and Outcome as Compared with Men. Int J Forensic Ment Health 9:(2):110-117

26. Kennedy J, Wilson C, Cope R (1995) Long-Stay Patients in a Regional Secure Unit. J Forensic Psychiatry 6(3):541-551

27. Tetley A, Jinks M. Huband N, Howells K, McMurran M (2012) Barriers to and facilitators of treatment engagement for clients with personality disorder: a Delphi survey. Personal Ment Health 6(2):97-110

28. Alexander R, Devapriam J, Michael D, McCarthy J, Chester V, Rai R et al (2015) Why can't they be in the community? A policy and practice analysis of transforming care for offenders with intellectual disability. Adv Ment Health Intellect Disabil 9(3):139-148 